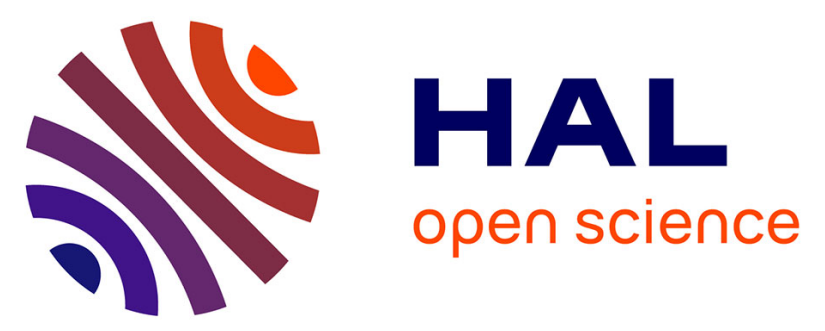

\title{
Yield, creep and wear properties of Ultra High Molecular Weight Polyethylene processed by High Velocity Compaction
}

David Jauffres, O. Lame, Gérard Vigier, Florence Dore, V. Fridrici

\section{To cite this version:}

David Jauffres, O. Lame, Gérard Vigier, Florence Dore, V. Fridrici. Yield, creep and wear properties of Ultra High Molecular Weight Polyethylene processed by High Velocity Compaction. Journal of Applied Polymer Science, 2008, 110 (5), pp.2579-2585. 10.1002/app.28697 . hal-00433974

\section{HAL Id: hal-00433974 https://hal.science/hal-00433974}

Submitted on 17 Jan 2022

HAL is a multi-disciplinary open access archive for the deposit and dissemination of scientific research documents, whether they are published or not. The documents may come from teaching and research institutions in France or abroad, or from public or private research centers.
L'archive ouverte pluridisciplinaire HAL, est destinée au dépôt et à la diffusion de documents scientifiques de niveau recherche, publiés ou non, émanant des établissements d'enseignement et de recherche français ou étrangers, des laboratoires publics ou privés.

\section{(c) (1) $\$$}

Distributed under a Creative Commons Attribution - NonCommerciall 4.0 International 


\title{
Yield, Creep, and Wear Properties of Ultra High Molecular Weight Polyethylene Processed by High Velocity Compaction
}

\author{
D. Jauffrès, ${ }^{1}$ O. Lame, ${ }^{1}$ G. Vigier, ${ }^{1}$ F. Doré, ${ }^{2}$ V. Fridrici ${ }^{3}$ \\ ${ }^{1}$ MATEIS, INSA-Lyon, CNRS UMR5510, Bât. B. Pascal 7 Avenue Jean Capelle, F-69621 Villeurbanne cedex, France \\ ${ }^{2}$ CETIM, 7 rue de la presse, BP802, F-42952 Saint Etienne cedex 9, France \\ ${ }^{3}$ LTDS, Ecole Centrale de Lyon, CNRS UMR5513, Bât. H10 36 Avenue Guy de Collongue, \\ F-69134 Ecully cedex, France
}

\begin{abstract}
A new processing method, high velocity compaction (HVC), is particularly adapted to process ultra high molecular weight polyethylene (UHMWPE). In a previous study, it has been shown that UHMWPE processed by HVC exhibits superior Young's modulus and significant ductility, owing to the preservation of nascent high crystallinity and high-quality sintering (Jauffrès et al., Polymer 2007, 48, 6374). In this article, a comparative study of yield, creep, and wear properties of HVC-UHMWPE and compression-molded UHMWPE is reported. HVC-UHMWPE has an enhanced re-
\end{abstract}

\section{INTRODUCTION}

Ultra high molecular weight polyethylene (UHMWPE) is a linear polyethylene whose molar mass exceeds 3 million $\mathrm{g} / \mathrm{mol}$. This extremely high molar mass imparts to its outstanding wear resistance, better than any other polymer. UHMWPE is used in several industrial applications requiring wear resistance (e.g., conveying systems) and in orthopedic implants (knee, hip, and shoulder implants). ${ }^{1,2}$

Because of its extremely high viscosity, UHMWPE is nonmelt processable, that is, it is not processable by conventional methods such as injection molding or extrusion. UHMWPE is produced by compression molding and ram extrusion. These processes have no viscosity limitation as they consist in applying elevated temperatures and pressures to sinter nascent UHMWPE powders. These powders are directly extracted from the polymerization reactor and have a particularly high crystallinity due to simultaneous crystallization and polymerization. This high crystallinity is irreversibly lost after the first melting. Because the temperatures employed for UHMWPE sintering are several degrees above

Correspondence to: O. Lame (olivier.lame@insa-lyon.fr). sistance to plastic deformation, likely due to its particular microstructure that improves its wear resistance. Concerning creep resistance, HVC-UHMWPE also exhibits enhanced performances thanks to its higher crystallinity. Consequently, HVC could be a new mean to improve UHMWPE performance for a wide range of applications, requiring high wear resistance, both in industrial and biomedical fields.

Key words: processing; polyethylene; yielding; creep

UHMWPE melting point, the polymer is thermodynamically melted and the crystallinity is lowered. Processing lasts for several hours and leads to a semifinished product that needs additional machining. ${ }^{1,2}$ This specific and long processing method limits UHMWPE applications.

A new process, high velocity compaction (HVC), enables processing of nascent UHMWPE powder thanks to a partial and controlled melting. ${ }^{3}$ HVC is a very promising process for UHMWPE, as it is less expensive than compression molding and ram extrusion. Indeed, the processing lasts only around $1 \mathrm{~min}$, and it is possible to produce parts without additional machining if they have a planar geometry. For example, it would be conceivable to obtain gears for industrial applications and parts for total joint prostheses directly.

HVC uses low processing temperature to preserve nascent UHMWPE. However, partial melting occurs and HVC-UHMWPE is thus formed of nascent highly crystalline polymer embedded in meltedrecrystallized polymer. ${ }^{3}$ The overall crystallinity is therefore higher than that of the compressionmolded UHMWPE that undergoes a complete melting during processing. The crystallinity degree, but also the size, morphology, and arrangement of the crystallites affect UHMWPE properties. In particular, when amorphous phase is above its glass transition (at ambient temperature) the crystal phase imparts 
stiffness to UHMWPE, and there is a direct relationship between modulus and crystallinity degree. ${ }^{4}$ It follows that, HVC-UHMWPE Young's modulus is improved compared to conventional UHMWPE, thanks to its higher crystallinity. On the other hand, the increased crystallinity reduces the exceptionally high fracture strain of UHMWPE. However, HVCUHMWPE fracture strains are suitable for a wide range of applications. In addition, it is possible to act on the processing parameters to adjust the crystallinity and hence the rigidity-ductility compromise. ${ }^{3}$

Wear and creep properties of UHMWPE have been widely studied, particularly for the total joint prosthesis application, using hip joint simulators or radiographic measurements. ${ }^{5,6}$ Notably, UHMWPE wear is believed to be initiated by plasticity-induced damage near the surface. ${ }^{5}$ Several research teams have attempted to improve UHMWPE wear resistance to increase prosthesis life. For instance, UHMWPE wear performance has been improved by electron beam or $\gamma$-radiation crosslinking. ${ }^{1,7,8}$ Significant dose of radiation creates free radicals that recombine to form crosslinks. A thermal treatment (annealing or remelting) is added to help the recombination of free radicals required to obtain a material resistant to longterm oxidative degradation. By increasing the density of the $\mathrm{C}-\mathrm{C}$ chemical bonds, crosslinking reduces intermolecular splitting and therefore wear. ${ }^{6}$ However, the improvement of wear resistance obtained by crosslinking comes at the expense of other crucial mechanical properties. Indeed, crosslinking alters the polymer structure, often leading to reduced modulus, ultimate properties, impact toughness, crack propagation resistance, and creep resistance. ${ }^{9-12}$ In particular, thermal treatments, originally introduced to improve oxidation resistance by reducing the number of free radicals, modify UHMWPE crystallinity and mechanical properties. For instance, it has been demonstrated that remelting leads to a significant decrease of the crystallinity degree and therefore of the modulus and yield stress. ${ }^{12}$ For these reasons, although crosslinked UHMWPE appears to be the new material of choice for hip prosthesis, ${ }^{8}$ several authors think that highly crosslinked UHMWPE would be unsuitable for applications where high stresses are expected, such as knee implants. ${ }^{9,11,13}$

Alternative methods both to improve wear resistance and to retain mechanical properties are currently under investigation. Interesting results have been recently published concerning multilayer nanocoating $^{14}$ and crosslinked UHMWPE doped with vitamin E. ${ }^{15}$ The use of vitamin $\mathrm{E}$ as an antioxidative additive replaces the thermal treatment causing the loss of mechanical properties.

It has also been attempted to improve wear performance of UHMWPE by developing new processing methods. For example, Simis et al. have used a

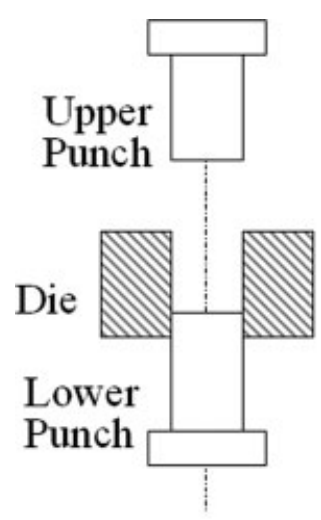

IMPACTS

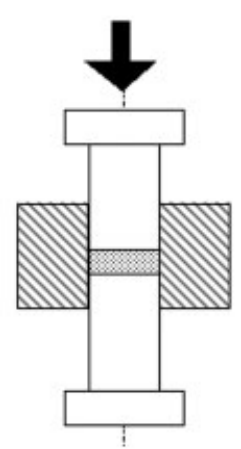

B - Compaction

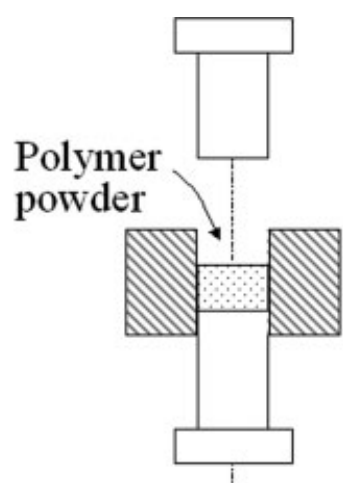

A - Powder filling

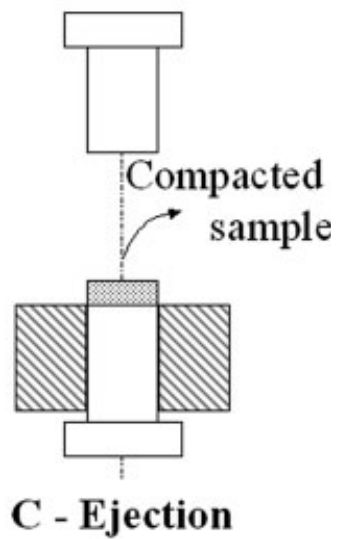

Figure 1 Schematic representation of the three steps of the HVC process.

high pressure process to increase the crystallinity, ${ }^{16}$ and Gaussens et al. have developed a specific shaping process to obtain an orientation of the chains below the wear surface. ${ }^{17}$

This study aims to see if HVC could be a new mean to improve UHMWPE wear resistance without reducing creep properties and modulus. Three chosen HVC-UHMWPE, produced in optimized conditions, are studied in comparison with a compressionmolded UHMWPE. Young's moduli and fracture strains of these materials, obtained in a previous study, ${ }^{3}$ are recalled. In the main section of the article, a detailed investigation of the yielding and plastic flow behavior of HVC and conventional UHMWPE is first reported. Then, tribological tests allow us to compare friction coefficients and wear resistance. Finally, creep performance is investigated to confirm the promising character of HVC-UHMWPE.

\section{EXPERIMENTAL}

\section{HVC of UHMWPE}

HVC consists in applying several controlled high energy impacts to a heated and powder-filled die (Fig. 1). The total (impact) energy, which is the first processing parameter, refers to the kinetic energy of 
TABLE I

Mechanical and Physical Properties of the Three Selected HVC UHMWPE and of Melt-Crystallized UHMWPE Tivar 1000. Young's Moduli were Measured by Three Points Bending Tests. Adapted from Ref. 3

\begin{tabular}{lcccc}
\hline & $\begin{array}{c}\text { Young's } \\
\text { modulus } E(\mathrm{MPa})\end{array}$ & $\begin{array}{c}\text { Tensile fracture } \\
\text { strain }\left(\varepsilon_{f}\right)\end{array}$ & $\begin{array}{c}\text { Crystal weight } \\
\text { fraction }\left(X_{c}\right)\end{array}$ & $\begin{array}{c}\text { Recrystallized } \\
\text { phase fraction }\left(f_{R}\right)\end{array}$ \\
\hline $115^{\circ} \mathrm{C}-4000 \mathrm{~J} / \mathrm{g}$ & $1090 \pm 100$ & $0.11 \pm 0.01$ & $0.63 \pm 0.01$ & $0.42 \pm 0.1$ \\
$120^{\circ} \mathrm{C}-3400 \mathrm{~J} / \mathrm{g}$ & $920 \pm 100$ & $0.3 \pm 0.1$ & $0.64 \pm 0.01$ & $0.54 \pm 0.1$ \\
$125^{\circ} \mathrm{C}-4300 \mathrm{~J} / \mathrm{g}$ & $750 \pm 100$ & $1.1 \pm 0.1$ & $0.56 \pm 0.01$ & $0.89 \pm 0.1$ \\
Tivar 1000 & $690 \pm 100$ & $\sim 1.5$ & $0.54 \pm 0.01$ & 1 \\
\hline
\end{tabular}

one impact multiplied by the number of impacts. The second parameter is the precisely regulated processing (tool) temperature.

A commercial powder produced by Ticona (Oberhausen, Germany), GUR 4113, was used to produce bulk UHMWPE by HVC. GUR 4113 molar mass, deduced from viscosimetric measurements, is 3.9 million $\mathrm{g} / \mathrm{mol}$. This nascent powder has a high crystal weight fraction $(68 \%)$, due to simultaneous crystallization and polymerization. After the first melting and recrystallization from the melt, a part of the crystallinity is irreversibly lost and the crystal weight fraction falls to $54 \%$. $^{3}$

It has been shown that, partial local melting occurs during HVC. It is supposed that the repeated impacts provoke enough self-heating at particle interfaces to melt some polymer. During cooling, recrystallization of the melted material would sinter the particles., 38 The nascent high crystallinity is partially lost and the crystal weight fraction of HVCUHMWPE ranges from 54 to $68 \%$ depending on the "fraction of recrystallized material." It has been demonstrated that the fraction of recrystallized material is governed by the processing parameters. An increase in total energy or in processing temperature results in a higher fraction of recrystallized UHMWPE. The fraction of recrystallized polymer $\left(f_{R}\right)$ was evaluated by two different methods based on differential scanning calorimetry results. The first method uses a mixing rule to obtain $f_{R}$ from the overall crystallinity degree of the sample and from the crystallinity degrees within each phase (nascent and recrystallized). The second method is based on the deconvolution of the two melting peaks. Finally, an average value of the volume fraction of recrystallized polymer over the two methods is presented in this article. Further details on this determination can be found in a previous paper. ${ }^{3}$ The recrystallized phase fraction strongly affects the mechanical properties. In particular, a low recrystallized phase fraction, hence a high crystallinity, leads to a significant gain in modulus when compared with conventional UHMWPE, but with a lower fracture strain. A high recrystallized phase fraction leads to a higher fracture strain, but at the expense of stiffness. ${ }^{3}$
For this study focused on wear and creep resistance, three HVC-UHMWPE were selected. They were processed at high total energy for three different processing temperatures. They differ by their recrystallized phase fraction and therefore their crystallinity and their mechanical properties (see Table I). Processing at $115^{\circ} \mathrm{C}$ favors modulus whereas processing at $125^{\circ} \mathrm{C}$ favors elongation.

A conventionally processed UHMWPE, the Tivar 1000 produced by PolyHiSolidur (Vreden, Germany), was also investigated for comparison.

\section{Tensile and creep tests}

Tensile tests were performed on a MTS machine to characterize HVC-UHMWPE yield and plastic flow behavior. The test temperature was $21 \pm 1^{\circ} \mathrm{C}$. A video-controlled testing system (VideoTraction ${ }^{\circledR}$ by Apollor) was used to measure true stress and true strain at a constant true strain rate of $1 \times 10^{-3} \mathrm{~s}^{-1} \cdot 19$ It is noteworthy that the precision for strains is about $1.5 \times 10^{-3}$, 19 which leads to a somewhat low relative precision at low strains $( \pm 15 \%$ at $\varepsilon=0.01)$ whereas precision is good at high strains $( \pm 1 \%$ at $\varepsilon$ $=0.15)$. Tensile specimens had a rectangular cross section of $1 \times 5 \mathrm{~mm}$ and a gauge length of $10 \mathrm{~mm}$.

Creep tests were performed on the same machine with similar specimens. The initial loading was

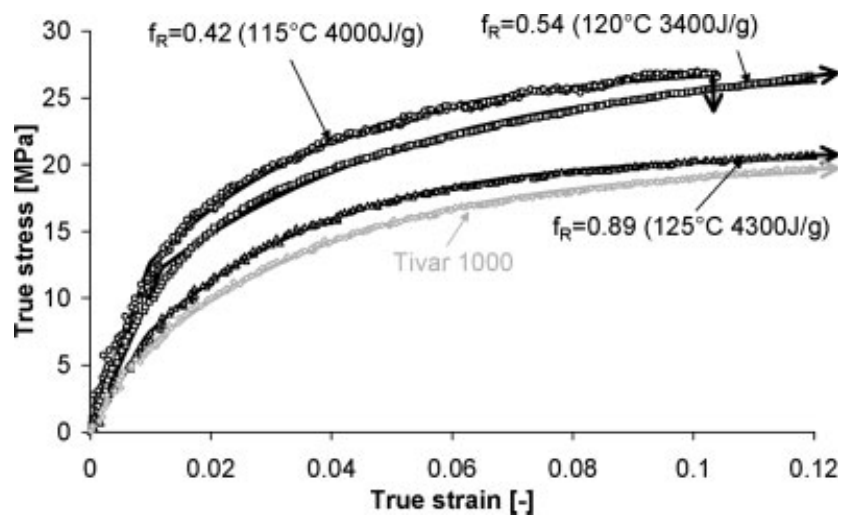

Figure 2 True stress-strain curves. Symbols = experimental data from tensile tests. Plain lines = elastic-plastic model. 
TABLE II

Elastic-Plastic Model Parameters

\begin{tabular}{lcrrrrr}
\hline & \multicolumn{1}{c}{$f_{R}$} & \multicolumn{1}{c}{$E(\mathrm{MPa})$} & \multicolumn{1}{c}{$\varepsilon_{y}\left(10^{-2}\right)$} & \multicolumn{1}{c}{$\sigma_{y}(\mathrm{Mpa})$} & $\alpha(\mathrm{MPa})$ & $\gamma$ \\
\hline $115^{\circ} \mathrm{C}-4000 \mathrm{~J} / \mathrm{g}$ & $0.42 \pm 0.1$ & $1300 \pm 200$ & $1 \pm 0.15$ & $12.6 \pm 0.2$ & 27 & -31 \\
$120^{\circ} \mathrm{C}-3400 \mathrm{~J} / \mathrm{g}$ & $0.54 \pm 0.1$ & $1000 \pm 200$ & $1.2 \pm 0.15$ & $12.3 \pm 0.2$ & 28 & -22 \\
$125^{\circ} \mathrm{C}-4300 \mathrm{~J} / \mathrm{g}$ & $0.89 \pm 0.1$ & $800 \pm 100$ & $0.9 \pm 0.15$ & $7.2 \pm 0.1$ & 21 & -33 \\
Tivar 1000 & 1 & $750 \pm 100$ & $0.7 \pm 0.15$ & $5.5 \pm 0.1$ & 20 & -28 \\
\hline
\end{tabular}

conducted at $1 \mathrm{~mm} / \mathrm{min}$; so that the creep stress was reached within less than $20 \mathrm{~s}$. Creep stress and creep time have been chosen to obtain sufficient deformation to reveal differences between the specimens. The nominal creep stress was $10 \mathrm{MPa}$, and the creep time was $\sim 20 \mathrm{~min}$. The true strain was recorded during the test by the video-extensometer.

\section{Tribological tests}

To characterize the wear and friction behavior of the materials, tribological tests were performed on a continuous rotation motion tribometer with a ball on flat contact configuration.

Surface preparation of the tested samples consisted in polishing the samples with decreasing roughness of the grinding paper (from grade 1200 to 4000). Water was used as lubricant during polishing. All samples were polished simultaneously on a multiple-head polishing machine to avoid differences in sample surface preparation. After polishing, samples were cleaned with water.

During wear tests, the counterbody was an AISI 52100 steel ball with a diameter of $12.7 \mathrm{~mm}$. The normal load was kept constant at $10 N$. The radius of the wear track and the rotation speed were $3 \mathrm{~mm}$ and 1 round per second, respectively, leading to a value of $19 \mathrm{~mm} / \mathrm{s}$ for the average linear instantaneous speed. The duration of the test was $30 \mathrm{~min}$ (1800 cycles, $34 \mathrm{~m}$ of friction length). No lubricant was used. The testing conditions were chosen to promote

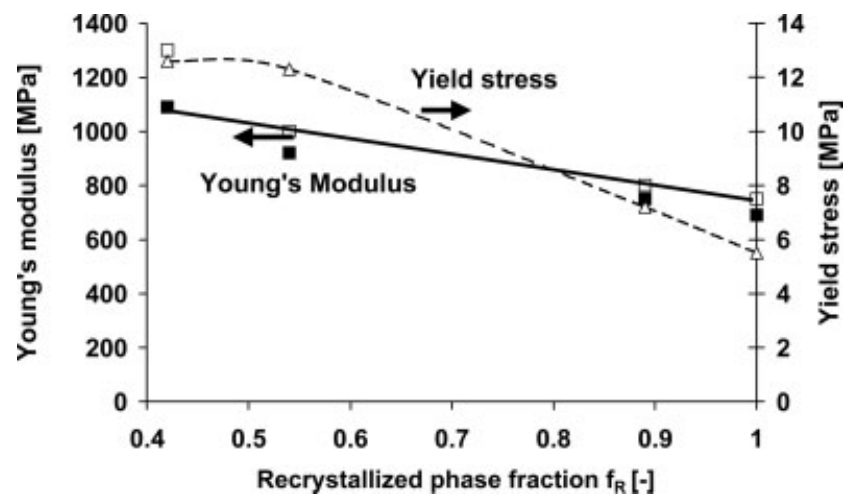

Figure 3 Young's modulus from bending tests (filled squares) and tensile tests (open squares) as well as yield stress (triangles) from tensile tests versus recrystallized phase fraction. wear of the UHMWPE samples, so that comparison was possible.

Normal and tangential forces were recorded during the test, enabling us to calculate the friction coefficient. Wear tracks were analyzed by postmortem with optical microscopy and tactile profilometry to determine the wear mechanism and to quantify the wear of the different specimens.

\section{RESULTS AND DISCUSSION}

\section{Yield and plastic flow behavior}

Yielding and plastic flow characterization is of prime interest, as UHMWPE is compressed above its elastic limit in an orthopedic bearing, ${ }^{9}$ and the resulting plasticity plays an important role in the wear mechanisms. 5,20

Thanks to the video-controlled testing system, the tensile mechanical behavior of conventional UHMWPE and of three chosen HVC-UHMWPE was investigated. The true stress-strain curves obtained by the video-controlled system are plotted in Figure 2.

The elastic behavior of the four chosen UHMWPE is limited to low strains (less than $\sim 0.01$ ), and the mechanical response quickly becomes nonlinear. It has been suggested that, effective strain in an UHMWPE orthopedic component does not exceed $0.12 .^{20}$ Consequently, to quantitatively analyze the four UHMWPE behaviors, stress-strain curves are fitted to the following elastic-plastic model until 0.12 strain:

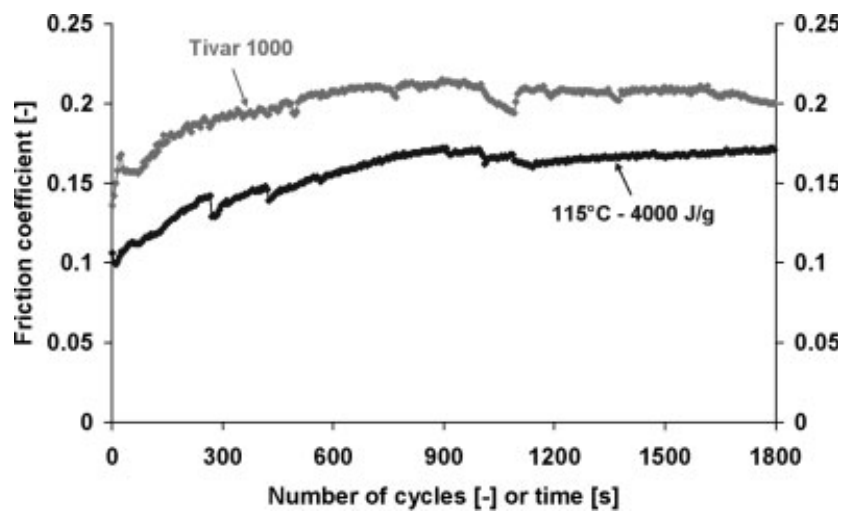

Figure 4 Evolution of the friction coefficient (tests at 1 round per second with a linear speed of $19 \mathrm{~mm} / \mathrm{s}$ and a normal load of $10 \mathrm{~N}$ ). 

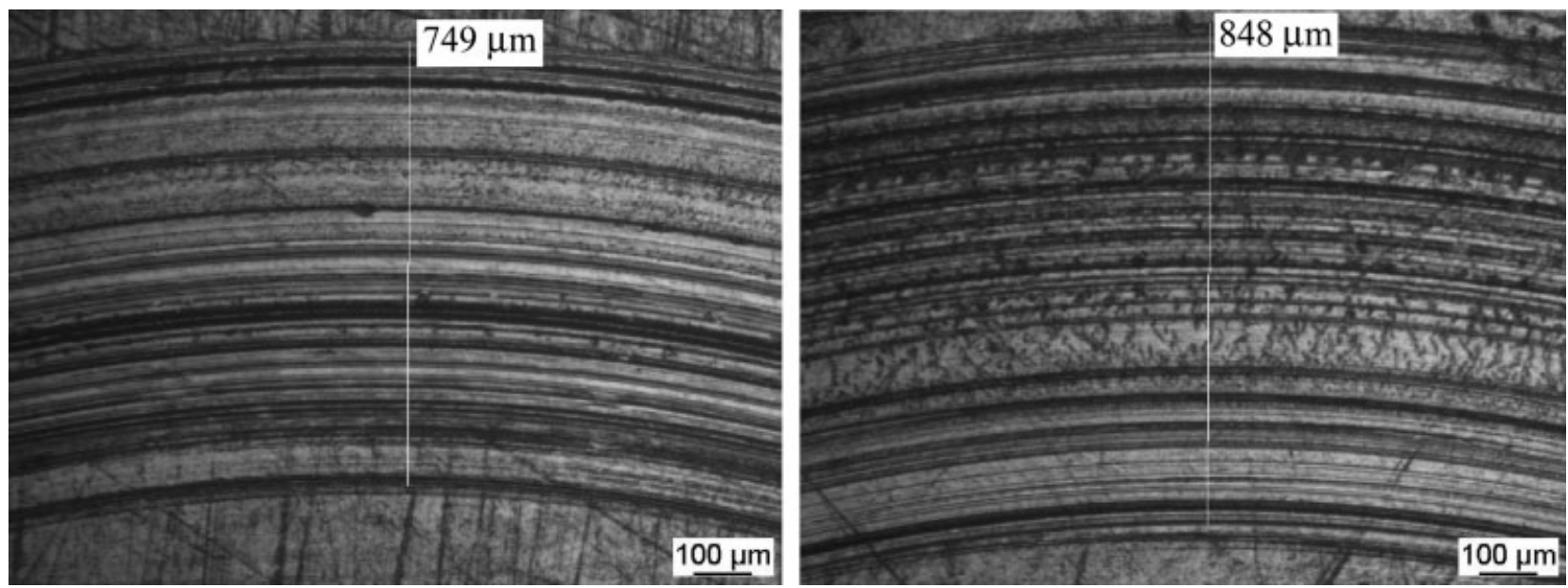

Figure 5 Optical microscopy of the wear scar (left: HVC-UHMWPE; right: Tivar 1000).

$$
\begin{aligned}
& \varepsilon \leq \varepsilon_{y} \rightarrow \sigma(\varepsilon)=E \varepsilon \\
& \varepsilon>\varepsilon_{y} \rightarrow \sigma(\varepsilon)=\alpha+\beta e^{\gamma \varepsilon}
\end{aligned}
$$

$E$ is the Young's modulus, $\varepsilon_{y}$ the yield strain, and $\alpha$ the asymptotic true stress at infinite strain. $\beta$ and $\gamma$ specify the form of the exponential plastic response.

At yield point, elastic and plastic models intersect and:

$$
\beta=\frac{E \varepsilon_{y}-\alpha}{e^{\gamma \varepsilon_{y}}}
$$

The model has therefore four independent parameters: $E, \varepsilon_{\mathrm{y},} \alpha$, and $\gamma$.

This elastic-plastic model allows us to define a yield point. Kurtz et al. have applied the same model to conventional UHMWPE and have shown that the obtained yield point actually corresponds to the appearance of nonrecoverable strain (until 6 days after loading). ${ }^{20}$ The parameters obtained by fitting the experimental points using a least square method are reported in Table II. The precision is only indicated for parameters having an obvious

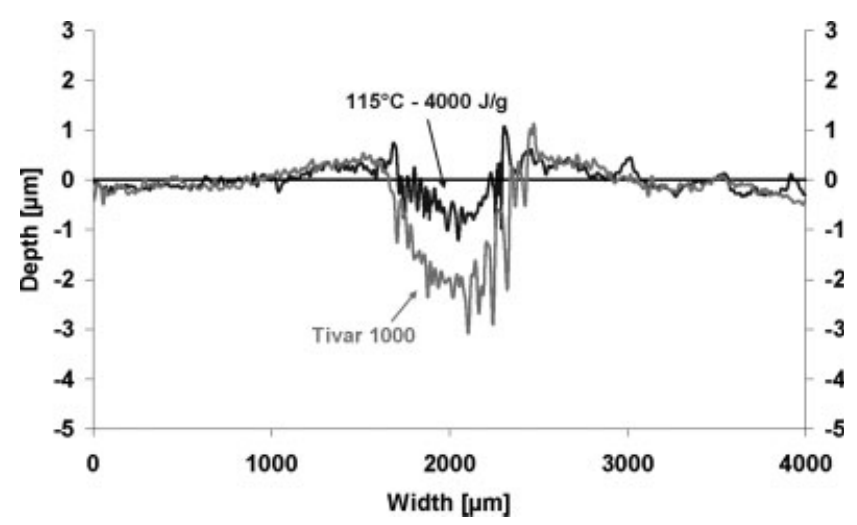

Figure 6 Transverse tactile profilometry of the wear tracks. physical sense. In addition, yield stress and Young's modulus are plotted versus the recrystallized phase fraction $f_{R}$ in Figure 3 .

The analysis of Table II and Figure 3 shows that:

- Modulus from tensile tests decreases with increasing recrystallized phase fraction and is in accordance with bending test results (Table I),

- Yield stress and $\alpha$ strongly decrease with increasing recrystallized phase fraction,

- Yield strain and $\gamma$ are less influenced by recrystallized phase fraction.

As already mentioned, in a semicrystalline polymer the crystallites are responsible for the material stiffness. It induces that the nascent phase is stiffer than the recrystallized one, which explains that Young's modulus decreases with the increasing recrystallized phase fraction. The evolution of Young's modulus follows a straight line, corresponding to a parallel mechanical coupling of both components.

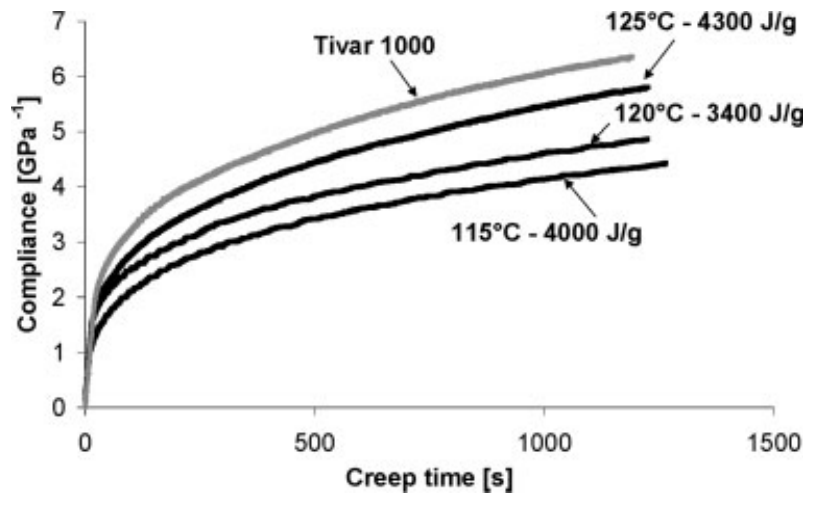

Figure 7 Creep compliance of HVC-UHMWPE and conventionally processed UHMWPE (Tivar 1000). 
TABLE III

Creep Properties

\begin{tabular}{lrcrc}
\hline & $\sigma_{y}(\mathrm{MPa})$ & $\begin{array}{c}\text { Initial true strain } \\
\text { at 10 }(\mathrm{MPa})\left(10^{-2}\right)\end{array}$ & $\begin{array}{c}\text { Creep compliance 10 (MPa) } \\
\text { and 1000 }(\mathrm{s})\left(\mathrm{GPa}^{-1}\right)\end{array}$ & $\begin{array}{c}\text { Recrystallized } \\
\text { phase fraction }\left(f_{R}\right)\end{array}$ \\
\hline $115^{\circ} \mathrm{C}-4000 \mathrm{~J} / \mathrm{g}$ & $12.6 \pm 0.2$ & $1 \pm 0.15$ & $4.1 \pm 0.2$ & $0.42 \pm 0.1$ \\
$120^{\circ} \mathrm{C}-3400 \mathrm{~J} / \mathrm{g}$ & $12.3 \pm 0.2$ & $1.4 \pm 0.15$ & $4.6 \pm 0.2$ & $0.54 \pm 0.1$ \\
$125^{\circ} \mathrm{C}-4300 \mathrm{~J} / \mathrm{g}$ & $7.2 \pm 0.1$ & $1.6 \pm 0.15$ & $5.5 \pm 0.2$ & $0.89 \pm 0.1$ \\
Tivar 1000 & $5.5 \pm 0.1$ & $1.9 \pm 0.15$ & $6.1 \pm 0.2$ & 1 \\
\hline
\end{tabular}

Yield stress also follows a similar trend, decreasing with the increasing recrystallized phase fraction. Therefore, nascent phase would have a higher yield stress than recrystallized phase, likely related to its particular microstructure characterized by a higher crystallinity.

To sum up, the tensile tests show that HVCUHMWPE exhibits a better resistance to plastic deformation.

\section{Wear and friction properties}

Tribological tests have been performed to evaluate the friction coefficients and the wear performance of the HVC-UHMWPE processed at $115^{\circ} \mathrm{C}$ and $4000 \mathrm{~J} /$ $\mathrm{g}$, that is, the more crystalline one, and the Tivar 1000 .

For both materials, the evolution of the friction coefficient during the test shows an initial increase and then a stabilization of the friction coefficient (Fig. 4). The values obtained for the HVC polymer are lower than for the conventional UHMWPE: 0.10 versus 0.115 for the incipient value and 0.16 versus 0.20 for the stabilized value.

Optical observation of the wear tracks (Fig. 5) clearly proves that the main wear mechanism is abrasion. In addition to abrasion grooves, the central part of Tivar 1000 wear surface shows the presence of troubled zones never observed on HVC sample that could be plasticity-induced damage. Observation of the counterbody shows no wear of the steel ball.

The width of the wear scar (mean value from eight optical measurements) decreased when using HVC-UHMWPE: from $891 \pm 32 \mu \mathrm{m}$ with Tivar 1000 to $711 \pm 57 \mu \mathrm{m}$ with HVC-UHMWPE processed at $115^{\circ} \mathrm{C}$ and $4000 \mathrm{~J} / \mathrm{g}$, indicating a better wear resistance of HVC-UHMWPE.

The increase of wear resistance is confirmed by tactile profilometry (Fig. 6): the wear scar with HVC-UHMWPE is less deep and less wide than with Tivar 1000. By averaging different profilometric measurements of the wear scar, it was calculated that the wear volume is divided by four when using HVC-UHMWPE. The profilometry also shows that, in both cases, there is plastic deformation (presence of pile-up of plastic strain matter around the wear scar) in addition to abrasion.
The improvement of wear resistance could be linked to the increase of polymer hardness (due to high crystallinity), which is then less prone to abrasion. The high yield stress of HVC-UHMWPE should also play a role in the improvement of wear resistance by reducing the plasticity-induced damage. The absence of troubled zone on HVCUHMWPE wear surface is consistent with this hypothesis. The decrease of friction coefficient is certainly a result of the UHMWPE Young's modulus increase: with higher stiffness of the polymer, the initial contacting area is smaller and, consequently, the lowing part of friction is decreased.

\section{Creep properties}

Creep resistance is a crucial property in numerous UHMWPE applications, notably orthopedic bearings. Indeed, significant creep of the UHMWPE bearing component can result in large deformation of the bearing surface and thus be problematic. ${ }^{21}$

Crosslinking, which has arisen enthusiasm, improves wear resistance $e^{1,5}$ but at the expense of crystallinity and related mechanical properties such as modulus and creep resistance. ${ }^{9-12}$

Tensile creep tests were carried out to evaluate the creep performance of HVC-UHMWPE. The creep compliance (strain divided by creep stress) is plotted in Figure 7. In addition, the compliance after $1000 \mathrm{~s}$

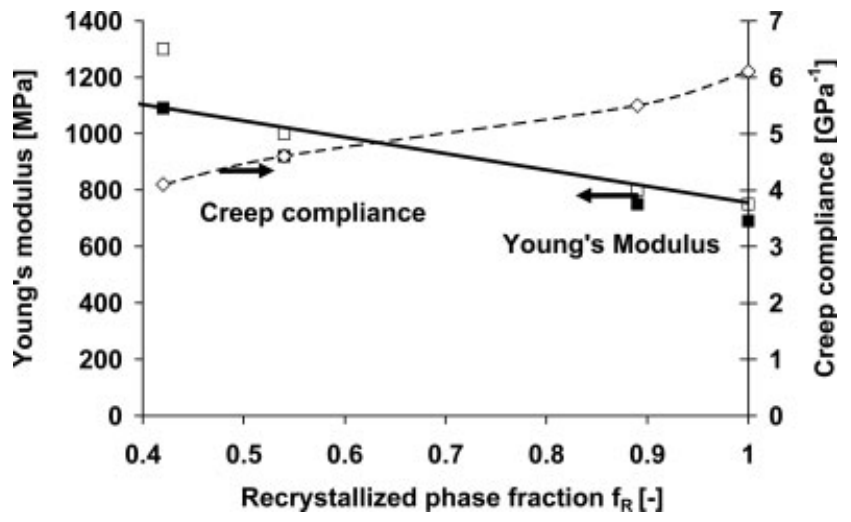

Figure 8 Young's modulus from bending tests (filled squares) and tensile tests (open squares) as well as creep compliance (diamonds) versus recrystallized phase fraction. 


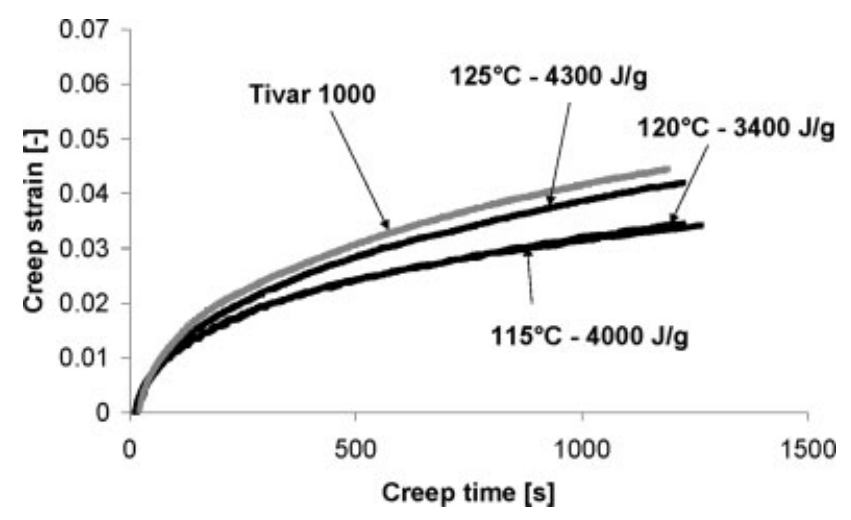

Figure 9 Creep strain, that is, initial true strain subtracted from total strain.

is reported for each material in Table III and plotted versus recrystallized phase fraction in Figure 8.

These results clearly show that HVC-UHMWPE has low creep compliance, increasing with the recrystallized phase fraction. Differences in creep compliance originate partially in different short-time properties that lead to different initial true strain at $10 \mathrm{MPa}$ (reported in Table III). A shift of the curves by subtracting the initial true strain allows us to obtain only the strain, resulting from creep (Fig. 9). It is observed that there is still a gradual increase in creep strains from the HVC-UHMWPE with the lowest recrystallized phase fraction to the conventionally processed UHMWPE. Creep rates also increase, revealing that the differences in strains tend to increase at longer creep time.

At this level of stress (10 MPa), creep is assumed to occur mainly in the amorphous phase, therefore higher creep resistance of HVC-UHMWPE is likely due to its lower amorphous content.

\section{CONCLUSION}

Our results show that HVC-UHMWPE wear resistance is improved compared to compression-molded UHMWPE (wear volume is divided by four). It has been demonstrated that enhanced wear performances mainly originate in the particularly high crystallinity of HVC-UHMWPE. In addition, it has been shown that the improvement of the wear resistance does not come at the expense of crystallinity and related mechanical properties such as modulus and creep resistance. Presently, the most common method to improve UHMWPE wear resistance is crosslinking. This technique leads to a reduced crystallinity and therefore the improvement of the wear resistance comes at the cost of modulus and creep resistance. On the contrary, HVC-UHMWPE presents at the same time a higher wear resistance, a higher modulus, and a higher creep resistance. It is believed that HVC could be a new interesting mean to improve life of UHMWPE components both for industrial and biomedical applications.

\section{References}

1. Kurtz, S. M.; Muratoglu, O. K.; Evans, M.; Edidin, A. A. Biomaterials 1999, 20, 1659.

2. Kelly, J. M. J Macromol Sci Polym Rev 2002, 42, 355.

3. Jauffrès, D.; Lame, O.; Vigier, G.; Doré, F. Polymer 2007, 48, 6374.

4. Crist, B.; Fisher, C. J.; Howard, P. R. Macromolecules 1989, 22, 1709.

5. Edidin, A. A.; Pruitt, L. A.; Jewett, C. W.; Crane, D. J.; Roberts, D.; Kurtz, S. M. J Arthroplasty 1999, 14, 616.

6. Wang, A. Wear 2001, 248, 38.

7. Muratoglu, O. K.; Bragdon, C. R.; O'Connor, D. O.; Jasty, M.; Harris, W. H. J Arthroplasty 2001, 16, 149.

8. Jasty, M.; Rubash, H. E.; Muratoglu, O. K. J Arthroplasty 2005, 20, 55.

9. Pruitt, L. A. Biomaterials 2005, 26, 905.

10. Lewis, G.; Carroll, M. Biomed Mater Eng 2001, 11, 167.

11. Gomoll, A.; Wanich, T.; Bellare, A. J Orthop Res 2002, 20, 1152.

12. Kurtz, S. M.; Villarraga, M. L.; Herr, M. P.; Bergstrom, J. S.; Rimnac, C. M.; Edidin, A. A. Biomaterials 2002, 23, 3681.

13. Ries, M. D. J Arthroplasty 2005, 20, 59.

14. Pavoor, P. V.; Gearing, B. P.; Muratoglu, O. K.; Cohen, R. E.; Bellare, A. Biomaterials 2006, 27, 1527.

15. Oral, E.; Christensen, S. D.; Malhi, A. S.; Wannomae, K. K.; Muratoglu, O. K. J Arthroplasty 2006, 21, 580.

16. Simis, K. S.; Bistolfi, A.; Bellare, A.; Pruitt, L. A. Biomaterials 2006, 27, 1688.

17. Gaussens, G.; Haudin, J. M.; Monasse, B. U.S. Pat. 4,747,990 (1988).

18. Jauffrès, D.; Lame, O.; Vigier, G.; Doré, F.; Chervin, C. J Appl Polym Sci 2007, 106, 488.

19. Quatravaux, T.; Elkun, S.; G'Sell, C.; Cangemi, L.; Meimon, Y. J Polym Sci Part B: Polym Phys 2002, 40, 2516.

20. Kurtz, S. M.; Pruitt, L. A.; Jewett, C. W.; Crawford, R. P.; Crane, D. J.; Edidin, A. A. Biomaterials 1998, 19, 1989.

21. Lee, K. Y.; Pienkowski, D. J Biomed Mater Res 1998, 39, 261. 